André Luís Valadares de Aquino*

Universidade Estadual de Campinas - Unicamp

\title{
O cavo amor e seus ruídos
}

\section{Resumo:}

Estudo sobre a relação de "mestria desviante" entre as obras de poesia de Carlos Drummond de Andrade e de Max Martins. Para tanto, compreende algumas linhas de força emblemáticas na poesia de Drummond em convergência e metamorfose na poesia de Max, no fim de 1940 e início de 1950. Segundo Benedito Nunes, no ensaio "Max Martins, Mestre-Aprendiz" (2001), a poesia de Drummond foi decisiva na formação da poesia de Max. É dominante no conjunto dos ciclos e no movimento descontínuo da obra de Max, como Benedito Nunes compreende a sucessão dos livros, o amor como procedimento erótico-erosivo, tópica fundamental da sua aprendizagem do desaprender em relação à poesia de Drummond.

Palavras-chave:

Max Martins, Carlos Drummond de Andrade, Poesia Brasileira Moderna, Erotismo

\section{Abstract:}

Study about the relationship of "deviant mastery" between the works of poetry by Carlos Drummond de Andrade and Max Martins. Therefore, it comprehends some emblematic lines of force in Drummond's poetry in convergence and metamorphosis in Max's poetry, in the late 1940s and early 1950s. According to Benedito Nunes, in the essay "Max Martins, Mestre-Aprendiz" (2001), Drummond's poetry was crucial in the formation of Max's poetry. It is dominant in the set of cycles and in the discontinuous movement of Max's work, how Benedito Nunes understands the succession of books, love as an erotic-erosive procedure, a fundamental topical of his learning of unlearning in relation to Drummond's poetry.

\section{Keywords:}

Max Martins, Carlos Drummond de Andrade, Modern Brazilian Poetry, Eroticism

1. O estudo inicialmente aborda a fortuna crítica sobre a poesia de Carlos Drummond de Andrade, com foco em um de seus momento centrais, de A Rosa do Povo (1945) ao Claro Enigma (1951), livros capitais da poesia brasileira em geral, com ecos na poesia escrita no Brasil imediatamente e até hoje, objetos de impasse crítico na história da sua recepção. No decorrer do trabalho, o interesse na poesia de Drummond acompanha o estudo da poesia de Max Martins, que teve seu primeiro livro, O Estranho (1952), como contemporâneo ao momento de emergência 
da obra poética mais decisiva de Drummond, do ponto de vista da história intelectual brasileira, momento marcado por um contraste entre lirismo engajado e classicização da forma, por uma polarização de concepções sobre poesia.

O trabalho, assim, tenta matizar a "solução" drumondiana em vista do tempo de uma certa crise da poesia e, principalmente, colocar em questão o lugar de Drummond na formação da poesia de Max. Consiste em acompanhar aspectos históricos e estéticos da crítica em torno de Drummond e de Max; no que tange especificamente à poesia de Max, compreender o tipo de assimilação e de transformação que opera em relação a Drummond, a sua maneira de resposta, de afastamento, de contra-assinatura, de depuração e de aprofundamento crítico, identificar a sua singularidade da diç̧ão lírica.

Tal apreciação dá a ver aspectos da construção sobre a obra de Drummond como ponto alto da poesia brasileira, sua colocação imediata como pedra incontornável no meio do caminho de poetas seus contemporâneos. ${ }^{1}$ A expressão "mestria desviante" ${ }^{2}$ para caracterizar a relação entre Drummond e Max anuncia o diálogo com o ensaio de Benedito Nunes, "Max Martins, Mestre-Aprendiz" (2001). Além de Benedito, que dedica parte do ensaio para apontar relações entre Drummond e Max, Luiz Costa Lima e Davi Arrigucci Jr. defenderam, também de maneira parcial, tal correspondência.

O presente ensaio tem em vista levantar leituras capitais que abrangem o "meio-dia" ${ }^{3}$ da escrita da poesia de Drummond - com ênfase nos estudos de José Guilherme Merquior, Vagner Camilo e Luiz Costa Lima - e, num só gesto, mapear questões e entender o que está em jogo no primeiro momento da escrita de Max. Constata-se que é principalmente na figuração do sujeito poético e na tematização do amor, tópicas emblemáticas em Drummond e em Max, que a poesia do escritor paraense produz um tipo de corrosão da influência drummondiana, isto é, assimilação e ultrapassagem, na forma de exploração do erotismo.

2. Segundo José Guilherme Merquior, no estudo influente Verso Universo em Drummond, tese de doutorado defendida na Sorbonne em 1972, a obra do poeta mineiro dramatizou uma dupla maturidade, aparentemente antitética. A rosa do povo e o Claro Enigma circunscrevem um arco tenso, que conjuga lirismo engajado e prosaísmo ao tédio pelo acontecimento e classicização da forma. Essa transformação da obra drummondiana em breve tempo tende a ser vista num sentido de polarização inconciliável: a concepção de poesia como participante, engajada, comprometida com a história, crítica dos processos sociais, comunicativa, utópica e de esperança na comunhão humana; e, por outro lado, como afastada da realidade, inoperante, hermética, formalista, autorreferencial, absenteísta e negativa.

Os principais críticos da obra drummondiana reconhecem a importância de contemplar em conjunto os livros da segunda metade da década de 1940 à primeira metade da década de 1950 como sucessão de uma madureza; inquietude diante do Eu, do mundo e da poesia; mescla de estilos; operação de um princípio de construção emblemático; de nenhuma maneira como superação, evolução ou oposição em fases. Aspectos que impõem o desafio e a complexidade da obra de Drummond. 
Vagner Camilo, na tese de doutorado Drummond: Da Rosa do Povo à Rosa das Trevas, desenvolvida na Universidade Estadual de Campinas, defendida em 1999, publicada em 2001, realiza na parte introdutória do trabalho uma leitura dos estudos da fortuna crítica de Claro Enigma em seus impasses, livro ao qual o autor reivindica para compreensão a consideração do contexto do pós-guerra e da crescente divisão do trabalho intelectual no Brasil. Segundo o crítico, a mudança operada pelo livro de 1951 deve ser tomada, na sua complexidade, em vista das razões externas da sua posição na obra geral drummondiana, na circunstância cultural e política brasileira. A expressão de Camilo, "guinada classicizante", para caracterizar a passagem entre a realização da Rosa do Povo e do Claro Enigma, sinaliza o diálogo crítico com José Guilherme Merquior.

Em Verso e Universo em Drummond, Merquior nota um deslocamento de estilo: entre o assunto prosaico e rotineiro e o tom sublime, conquista de Charles Baudelaire, reinante no livro de 1945; e a abstração, como maneira de relação com a sociedade, adotada no livro de 1951. Do ponto de vista da teoria do romanista Erich Auerbach, Merquior define a oscilação entre o "estilo mesclado" e o "estilo mítico". Na leitura do crítico, o estilo drummondiano se sucede necessariamente de maneira impura:

Drummond elabora, num primeiro momento (1925-1940), uma versão personalíssima de um gênero de elocução caro à poesia moderna desde Baudelaire: 'o estilo mesclado' (Auerbach), resultantes da fusão do tom problemático com as referências 'vulgares'.

[...] No segundo momento evolutivo (1940-45), chegada ao auge de sua mestria técnica, esboça uma separação entre estilo mesclado e uma elocução re-'purificada'.

[...] No terceiro momento evolutivo (1946-58), dominado por Claro Enigma, o afastamento da escrita mesclada e a adoção dos módulos métricos regulares retomam a forma de uma estilo 'mítico', no sentido de Hermann Broch: um estilo abstrato em relação às figurações realistas da cena social. (Merquior 2012: 325)

A visada estilística de Merquior abrange os processos de elaboração da forma e a significação sociológica e ideológica da lírica de Drummond, especialmente a reflexão sobre a evolução do regime patriarcal no Brasil. Portanto, o título do estudo, Verso e Universo em Drummond, sugere a relação entre poesia e sociedade, ou seja, o interesse na investigação da imanência do conteúdo social na linguagem estética.

Os aspectos humorístico e, ironicamente, autobiográfico, no primeiro lirismo de Drummond - em Alguma Poesia (1930), Brejo das Almas (1934) e Sentimento do Mundo (1940) - se adensam e se dissipam, "Drummond sabe agora [no momento central da sua obra, entre 1940 e 1950] que a poesia 'não é a arte do objeto' [...] mas antes 'a arte do nome do objeto'" (Merquior 2012: 112), eco da concepção de lírica moderna para Stéphane Mallarmé, para quem não se faz poesia com ideias, mas com palavras. ${ }^{4}$ No entanto, em José e A Rosa do Povo, são os poemas mais subjetivos que operam uma significação sociológica de maior voltagem, como em "O mito": 


\author{
Sequer conheço Fulana, \\ Vejo Fulana tão curto, \\ Fulana jamais me vê, \\ Mas como eu amo Fulana. \\ [...] \\ E Fulana diz mistérios, \\ Diz Marxismo, rimmel, gás, \\ Fulana me bombardeia, \\ No entanto sequer me vê. \\ [...] \\ Sou eu, o poeta precário \\ Que fez de Fulana um mito, \\ Nutrindo-me de Petrarca, \\ Ronsard, Camões e Capim; \\ [...]. \\ (Andrade 2012: 64, 68, 69)
}

No poema nota-se o aspecto da desidealização do eu e da temática amorosa, ao mesmo passo, o recurso à poesia amorosa clássica, a blague da condição do poeta no mundo moderno e a ironia da comunhão política.

Em poemas de Claro Enigma, na leitura de Merquior, a "perspectiva biográfica", assumida por Drummond nos primeiros livros, dá lugar à "poesia de investigação existencial de tom impessoal" (Merquior 2012: 181), embora os poemas filosóficos de Drummond já estivessem presentes em A Rosa do Povo. Merquior identifica que nos livros do terceiro lirismo a especulação metafísica advém de situações "vividas", sem se configurar como "poesia do vivido", no caso dos poemas amorosos, constituem forma de pensamento sobre Eros, não apenas expressão emotiva e figuração de sentimento.

No tocante ao tema amoroso, a poesia de Drummond inseria uma tensão entre individualismo e preocupação coletiva. Vagner Camilo destaca que a solidariedade humana seria o sentimento por excelência de uma literatura participante. A concepção de literatura engajada, que dava forma à criação artística nas décadas de 1930 e 1940 no Brasil, mediante à circunstância de estado de exceção, demandava uma ideia específica e restritiva do papel do escritor, do ponto de vista do Partido Comunista Brasileiro (PCB). Em 1942, Drummond participou da fundação da Associação Brasileira de Escritores (ABDE). Em 1949, assumiu posição tensa no famoso Congresso, marcado pela polarização interna. Drummond, apesar da "condenação do apego a sentimentos individualistas e burgueses como o amor" (Camilo 2001: 75), o retoma e dá ênfase na lírica de Claro Enigma.

Camilo admite de modo especial a prosa de Drummond, do livro Passeios na Ilha, de 1952, as correspondências e os diários do escritor, para compreender o desencanto em relação ao $\mathrm{PCB}$, a mudança do projeto eminentemente participante de $A$ rosa do Povo ao projeto marcado 
pelo pessimismo de Claro Enigma. Drummond, assim, assumiu uma posição dialetizante diante do contexto de polarização ideológica e de crise da linguagem poética:

[...] de um lado, proteger-se da retórica alienante e estéril em que incorreu a geração de 45 no seu intento de firmar o território autônomo da poesia, em reposta à especialização do trabalho artístico então em curso; de outro, escapar ao comprometimento político-partidário de muitos artistas participantes que sujeitaram ao dogma jdanovista. (Camilo 2001: 96)

A tensão dialética constitutiva da obra de Drummond, pontua Camilo, formulou uma espécie de "certeza duvidosa" na esperança, expressão retomada de Gilberto Mendonça Teles, em A Estilística da Repetição, de 1976. A definição paradoxal matiza o que se põe em causa na fatura estética e na reflexão da história em Claro Enigma, o desígnio inescapável da poesia em ressoar um canto mudo ou que "penetra surdamente" (imagem que já estava em A Rosa do Povo) e a renúncia ante os acontecimentos, ao mesmo tempo em que dá a ver, nessa atitude, o funcionamento mesmo da "maquinação do mundo",5 a destruição da poesia pela exploração capitalista. $\mathrm{O}$ desbastamento da linguagem, que atinge o mais alto grau em Claro Enigma, pode ser lido, defende Camilo, como especialização da linguagem poética, como processo de autonomização de um campo intelectual, e, ainda, na perspectiva de uma desmistificação da linguagem, de denúncia da doxa na compreensão da realidade social, no limite, de eliminação da polaridade pelo paradoxo. Nesse sentido, qual seja a dialética fundamental na obra drummondiana do pós-guerra: a renúncia e a denúncia.

A compreensão da história em Drummond é colocada em primeiro plano na leitura de Luiz Costa Lima, em Lira e Antilira, de 1968, revista e reeditada em 1995. Para Costa Lima, na poesia de Drummond de A Rosa do Povo e do Claro Enigma opera de modo paradigmático o princípio operacional da corrosão, fundado em dois polos, o polo da escavação e o polo da opacidade, que "podem-se sobrepor, cruzar-se ou, ao contrário, um ao outro anular" (Lima 1995: 151). A corrosão-escavação está ligada à ideia de luta, enquanto a corrosão-opacidade está ligada à ideia de interdição. Segundo o crítico, embora no livro de 1951 se perca em alguma medida a corrosão-escavação, nele observa-se a frequência das duas projeções, assim como no livro de 1945.

A lírica amorosa em língua portuguesa tem em Claro Enigma, em poemas como "Amar", "onde regressa o melhor Drummond" (Lima 1995: 182), um ponto alto: "Amar a nossa falta mesma de amor, e na secura nossa / amar a água implícita, e o beijo tácito, e a sede infinita" (Andrade 2002: 263). Essa retomada da dicção amorosa, a que refere Costa Lima, remete ao primeiro Drummond, de Alguma Poesia, que dispõe de um conjunto extensivo de poemas sobre o amor, e de Brejo das Almas, em que o poema "Não se mate", nos seus últimos versos, prepara a tematização do "tempo-corrosão": "O amor no escuro, não, no claro / é sempre triste, meu filho, Carlos" (Andrade 2002: 57). "Amar", de Claro Enigma, e "Não se mate", de Brejo das Almas, são poemas em que o amor é experiência do tempo em treva: 
No escuro ou no claro, onde o amor se situa? No claro que é escuro (formulação primeira do que depois se decifrará na expressão 'Claro Enigma'). No claro do dia, incluso, na cegueira do tempo, onde desembocam misturados, ruídos, choques, seres e sentimentos. (Lima 1995: 142)

O caráter antilírico da poesia de Drummond passa justamente pelo tema amoroso, na medida em que não se basta na transmissão de sentimentos pessoais. 0 distanciamento da mera expressão sentimental é assegurado pela ironia corrosiva do eu. Em Claro Enigma há o "amor de madureza" (Lima 1995: 183), amor na "falta mesma de amor" e no "desamor" (Andrade 2002: 263), na diferença inconciliável, corrosão do amor e amor corrosivo, amor insuficiente e ilimitado. O amor em Claro Enigma tem um sentido de opacidade.

Para Costa Lima, em Drummond a poesia do amor, da família ou da História é invenção de memória, irredutibilidade ao presente e ao acontecimento. Complexa relação com o tempo, que não deixa de estabelecer uma captação do real: o tempo vivido como corrosão.

3. Imediatamente após a publicação de A Rosa do Povo, de 1945, e de o Claro Enigma, de 1951, Max Martins publicou seu primeiro livro de poesia, O Estranho, em 1952. O momento da poesia brasileira em torno de 1952 é atravessado pela exigência ambivalente de vozes participantes e de conquista da formalização específica da linguagem poética, arco histórico de aparecimento das expressões emblemáticas da poesia brasileira, entre elas, O Cão sem Plumas (1950), de João Cabral de Melo Neto; O Rei menos o Reino (1951), de Augusto de Campos; Invenção de Orfeu (1952), de Jorge de Lima; Romanceiro da Inconfidência (1953), de Cecília Meireles; Contemplação de Ouro Preto (1954), de Murilo Mendes.

Benedito Nunes foi para Max Martins, desde $1942,{ }^{6}$ companheiro de geração na capital paraense. Resultado dessa convivência intelectual e amizade intensiva, o ensaio "Max Martins, Mestra-Aprendiz", de 2001, figura como uma espécie de documento da relação entre o pensamento de Benedito Nunes e de Max Martins. A poesia de Max é para Benedito lugar emblemático da convergência natureza e cultura, temas por excelência do seu interesse filosófico e crítico. Benedito foi em relação a Max testemunha da gênese e intérprete privilegiado da sua poesia.

No ensaio de 2001, prefácio dos Poemas Reunidos: 1952-2001, de Max, Benedito relata que a sua estreia na crítica se deu na apreciação da poesia de Max, de O Estranho, em 1952. Tendo sido prefaciador de livros seguintes, como no ensaio instigante "Recensão Crítica de H’Era", de $1973,{ }^{7}$ é no ensaio de 2001, na parte III, que aponta novamente e matiza a relação entre Drummond e Max, como um topos fundamental para a compreensão da formação e da transformação das linhas de força da poesia de Max e, desse modo, da construção em torno da obra de Drummond como, desde já, paradigmática.

Para comentar a obra de Max, Benedito destaca sobre a obra de Drummond, em A Rosa do Povo, a configuração de um "humor doloroso e irônico" (Nunes 2001: 30), já constante no primeiro Drummond; e, em Claro Enigma, a permanência do "traço jocoso, a tonalidade trágica dos graves contrastes existenciais [...]" (Nunes 2001: 30). Em Alguma Poesia, Brejo das Almas, José e Sentimento do Mundo já estaria formulado "o cômico do cotidiano [...], a lírica prosaica, 
do vulgar [...] que O Estranho [de Max] tão bem absorveu" (Nunes 2001: 30).

O Estranho mantém com o primeiro Drummond a convergência formal da lírica fragmentária, conquista do modernismo de 1922, contudo, em Max e Drummond, apresentando-se como depuração, não como mero recuo. $\mathrm{O}$ "rápido registro, à maneira de tomada fotográfica" (Nunes 2001: 31), no poema de Max "Muaná da Beira do Rio", é um procedimento contíguo ao poema de Drummond "Cidadezinha Qualquer":

\section{Cidadezinha Qualquer}

Casas entre bananeiras

mulheres entre laranjeiras

pomar amor cantar.

Um homem vai devagar.

Um cachorro vai devagar.

Um burro vai devagar.

Devagar... as janelas olham.

Eta vida besta, meu Deus.

(Andrade 2002: 23)

\section{Muaná da Beira do Rio}

A velha matriz branca

De portas largas

Sozinha na praça

Olhando o rio sujo.

Montaria dançando. Tarde preguiçosa.

Rua inquieta. Jornal do prefeito

Com santo na primeira página.

E a usina bufando, bufando,

Engolindo lenha.

Na janela do posto do Correio

Um cacho de bananas balançando.

(Martins 2001: 356) 
Os poemas convergem ainda do ponto de vista da imagística, de maneira explícita o primeiro verso de Drummond figura como uma espécie de variação no último verso de Max, variação que funciona, assim, como inversão e aprofundamento: "Muaná" é uma "cidadezinha qualquer" no sentido drummondiano, como Itabira, que resguardava, na memória do poeta, formas de vida da modernidade periférica do Brasil, a estrutura agrária, a convivência do ritmo de lentidão, a carroça, e da notícia; da novidade da fábrica e das velhas casas (por onde se abrem os poemas); o tédio e a melancolia corrosiva do amor.

Benedito Nunes notou a constante na obra de Max, desde 0 Estranho, do contraste do espaço interior e do espaço exterior, a casa e a natureza, espaços intercambiantes nos poemas e, muitas vezes, inextrincáveis.

As imagens da memória em Drummond são interpretadas como "memória involuntária" (Wisnik 2018: 33) ou como invenção de memória (Lima 1995: 184); assim como, em Max, o "eu" é interpretado como "afirmação do sujeito individual, [que] ainda constituía a matéria-prima da ficção poética" em 0 Estranho (Lima 2020), ou como "auto-irrisão, como mecanismo humorístico de encenação autobiográfica" (Nunes 2001: 32).

Costa Lima, crítico experiente em torno da obra drummondiana, publicou um ensaio sobre a obra de Max muito recentemente, na página online da Revista Cult, de 24 de junho de 2020, "Max Martins: A excepcionalidade Paraense". O ensaio percorre a obra global de Max, constituída de dez volumes de poesia, a exceção de três livros que, expõe o crítico, ultrapassam os seus interesses específicos, A fala entre parênteses (1982), Marahu Poemas (1992) e Colmando a Lacuna (2001). Costa Lima identifica como ponto alto da obra de Max o livro Caminho de Marahu, de 1983, para justificar sua eleição analisa o poema "Madrugada as Cinzas":

Madrugada, as cinzas te saúdam

De novo moldas contra a penumbra, maldas

o galo do poema, a tua armadilha, o fogo

adendo cego nos desvãos do sangue

De novo ergues sobre a areia, madrugada, o corpo

amaldiçoado duma palavra, a teia rediviva

e a sombra crespa do desejo negro

eriçando o pelo, o cão da página

Riscos se entrelaçam, fisgam a mosca do deleite

e já a ruína

tenaz, fibrosa, agônica sob a folhagem, mostra

o olho menstrual e sádico do destino

Um sonho cresce e se entumece

no rumos sexual dos ecos se compondo 
E batem à porta

- os gonzos, os gozos da ferrugem

o rangido longínquo vagindo de outro mundo

De tudo, madrugada, a dúvida traça um rosto

exposto neste espelho contra o sol: O soletrado

calcinado

(Martins 2001: 140)

Costa Lima defende que ocorre na obra de Max, de maneira consolidada em Caminho de Marahu, o abandono da expressão egoiga "[...] em favor de sua materialidade corpórea, que é também a da palavra. $O$ duplo corpo adensa a composição da estrofe. $O$ corpo do agente remete ao corpo daquilo com que ele trabalha, a palavra" (Lima 2020). A dicção própria de Max em relação a Drummond, também na leitura de Costa Lima uma relação fundamental, forma-se na exploração do tema amoroso. A metalinguagem em Max, presente desde 0 Estranho (atente-se, por exemplo, aos poemas "O Estranho" e "Poema") adquire uma dimensão surpreendente na reflexão sobre o corpo do autor (a letra, o autorretrato, a figuração do poeta) e o corpo da linguagem, "a correspondência entre eros e poiesis" (Lima 2020).

A leitura de Benedito Nunes já contemplava essa intensificação da temática amorosa, o erotismo como linha de força central na poética de Max Martins. A busca de formalização da poesia de amor, evidente em $O$ Estranho, mescla versos livres e fragmentários ao recurso ao soneto e à elegia, sinal, desde já, de estilo impuro e de classicização da mensagem estética, que se colocava, na situação poética brasileira, como vetor da criação e da relação com a história e com a sociedade. ${ }^{8}$ Os poemas de forte inflexão clássica aparecem, ainda em "O Estranho, em intercalação com "poema[s] [que] não escolhe[m] palavras que pudessem parecer nobres, tampouco opta[m] por alguma ordem" (Lima 2020).

O livro emblemático de Max, do ponto de vista da leitura de Costa Lima, Caminho de Marahu, recebeu apreciação crítica de Davi Arrigucci Jr., em mais de um lugar, entre eles no ensaio de prefácio à edição da poesia completa de Max, publicada entre 2015 e prevista para ser concluída neste ano, pela Editora da Ufpa. Na leitura de Arrigucci Jr., o aspecto do "eu" na poesia de Max é uma aprendizagem da poesia de Drummond, do "dizer ensimesmado de Drummond [...]", que no poeta paraense se transforma em "movimento expansivo [...] para o aprendizado de fora [...] insulamento interior [...] para além de qualquer ilhamento espiritual que pudesse encontrar apoio na situação geográfica de Belém" (Arrigucci Jr. 2015: 14-15).

No ensaio "O amor em seus abismos: A poesia erótica de Max Martins", de 2014, Arrigucci Jr. defende que a formação de Max em diálogo com a obra drummondiana é atravessada pela ironia corrosiva do eu:

A assimilação do humor reflexivo à maneira de Drummond se dá, por isso, com a perfeita fami- 
liaridade que aproxima poetas de uma mesma linhagem, sem impedir ou perturbar a configuração de traços próprios do aprendiz que se inicia; antes, pelo contrário, reafirma sua propensão central - acentuada, além disso, por um movimento interior que procurava cada vez mais cavar em si mesmo, numa matéria singular e própria, enfrentando todo o tempo as dificuldades para exprimi-la de forma pessoal, por mais intrincada que fosse. (Arrigucci Jr. 2014).

O tema amoroso, nesse caso, resulta de uma só escavação que atinge três dimensões singularizantes da poesia de Max: o eu na busca do estranho de si mesmo; o outro, objeto de amor, perscrutado num movimento dialético entre o concreto e o místico, o amor sob a lei do outro; e a corporificação das palavras em fusão erótica, em que se conjugam o eu e o tư ${ }^{9}$ na sua diferença.

Assim, a relação entre Drummond e Max se configura como uma mestria desviante, na expressão de Benedito Nunes, "uma aprendizagem do desaprender" (Nunes 2001: 33). As cinco partes do ensaio de Benedito dão conta de aspectos que envolvem a formação e a transformação da poesia de Max, o nascimento da poesia de Max na imitação da poesia de Drummond e na diferenciação e estranhamento do referente.

É dominante no conjunto dos ciclos e no movimento descontínuo da obra de Max, como compreende Benedito a sucessão dos livros, o amor como procedimento "erótico-erosivo" (Lima 2020). A leitura da "Lira e Antilira", no caso drummondiano, concentra-se sobremaneira no desgaste do tempo, em luta e em recuo. Em relação à poesia de Max, "Em Drummond, o que chamamos de princípio corrosão não contamina o erótico, que se dispõe em destacá-lo, na imagem orientada pela memória. É em Max Martins, sim, que tal fusão opera" (Lima 2020).

4. Para Costa Lima, em Max "a poesia e o amor seguem conjuntamente, uma mesma curva de declínio, de turvação, de esvaziamento" (Lima 2020). É uma conquista de Drummond e de Max, além de Cabral e de outros poetas seus contemporâneos, a experimentação do ruído e a ultrapassagem da música altissonante. Pode-se associar a poética de Max a uma tradição antilírica da poesia brasileira, em que o tema amoroso não corresponde ao confessional, ao sentimental e ao melodioso, mas opera uma despersonalização do eu ${ }^{10}$ e um desencantamento da música,

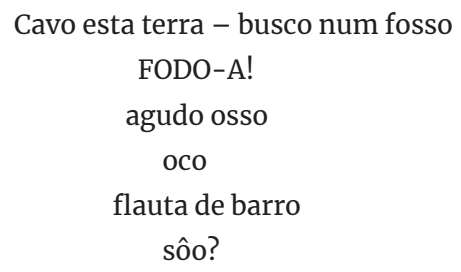

(Martins 2001: 280)

em que o amor é apresentado na sua contraparte de estranhamento. A poesia de Max opera uma sonoridade cáustica, choques sonoros e visuais insuspeitados, som e sentido em união carnal, cuja superfície funda é perecível, "o cavo amor e seus ruídos"."11 


\section{NOTAS}

* André Luís Valadares de Aquino é doutorando em Teoria e História Literária na Universidade Estadual de Campinas, com bolsa pelo Conselho Nacional de Desenvolvimento Científico e Tecnológico, CNPq. Foi professor na Universidade Federal do Pará e no Instituto Federal do Pará, atualmente é professor na Secretaria de Estado de Educação do Pará. Pesquisa poesia brasileira moderna e contemporânea, com tese sobre a obra de Max Martins.

${ }^{1}$ Sobre o interesse que a poesia de Drummond exerceu sobre poetas do seu tempo, John Gledson, em Influências e impasses: Drummond e alguns contemporâneos, de 2003, é um estudo referencial. Destaca-se o caso de João Cabral de Melo Neto, em que o recurso imediato a Drummond, no primeiro livro do poeta pernambucano, Pedra do Sono, de 1942, foi objeto de debate constante na sua fortuna crítica.

${ }^{2}$ Com essa expressão há a menção ao título do ensaio incontornável na fortuna crítica de Max Martins, "Max Martins, Mestre-Aprendiz" (2001), em que Benedito Nunes vê na obra de Max em relação à obra de Drummond assimilação e rasura na constituição de sua particularidade da dicção lírica.

3 Expressão de José Guilherme Merquior para referir ao "momento meridiano" da obra de Drummond, ou seja, quando simultaneamente dirige o olhar para trás e para frente: recupera recursos do primeiro lirismo, de modo especial o humorismo; e projeta a reflexão classicizante, a ser dominante nos livros da década de 1950.

${ }^{4}$ Menção ao famoso diálogo entre Mallarmé e o pintor Degas, que afirmava ter ideias sem conseguir fazer versos. Em resposta, o poeta de Um Lace de Dados afirma: “Absolutamente não é com ideias, meu caro Degas, que se fazem os versos. É com palavras" (apud Valéry 1991: 208).

${ }_{5}^{5}$ Título do livro recente de José Miguel Wisnik, A Maquinação do Mundo: Drummond e a Mineração, de 2018. Estudo que evoca desde título o poema emblemático de Claro Enigma, "A máquina do mundo", que em Drummond é signo da operação classicizante e da recusa da história. A leitura de Wisnik alcança a significação cava da poesia de Drummond no livro a priori de desistência do acontecimento: a tragédia do destino mineral de Itabira e a derruição do mundo, a dialética do local com o universal. ${ }^{6}$ A dissertação de mestrado de Melissa Alencar, intitulada 1952: A poesia de O Estranho de Max Martins, defendida na Universidade Federal do Pará, em 2011, demarca o início da amizade entre Max Martins e Benedito Nunes, em torno de 1942 (Alencar 2011: 104). A amizade e a interlocução das ideias se desenvolveram a partir das reuniões no contexto do "Grupo dos Novos" e, no decorrer daquela década, em torno do Suplemento Literário da Folha do Norte, fundado pelo escritor Haroldo maranhão, por meio do qual testemunharam a circulação de obras nacionais e internacionais do modernismo contemporâneo e publicaram suas primeiras realizações de escrita poética e crítica.

${ }^{7}$ Até a data de publicação desse ensaio, publicado na Revista Colóquio/Letras, da Fundação Calouste Gulbenkian, n. 14 julho de 1973, Benedito já havia publicado, por exemplo, o estudo muito caro na fortuna crítica de Clarice Lispector, o dorso do tigre, de 1969.

${ }^{8} \mathrm{O}$ estudo sobre estilo de Max Martins foi desenvolvido na tese de doutorado de Wenceslau Otero Alonso Jr., Estilo poético na obra de Max Martins, defendida recentemente, em 2019, no Programa de Pós-Graduação em Filologia e Língua Portuguesa, da Universidade de São Paulo (USP). Na história da fortuna crítica de Max Martins, foi a segunda tese de doutorado defendida sobre a sua obra. A primeira tese foi desenvolvida no Programa de Pós-Graduação em Literatura Brasileira, também da USP, por Paulo Vieira, intitulada Arte, erotismo, natureza e amizade: Os diários de Max Martins, de 2014. A obra de Max Martins tem recebido maior investimento de leitura crítica após a morte do escritor.

${ }^{9}$ A poética de Max Martins, na leitura Eduardo Sterzi, no ensaio "Max Martins: Riscos, Rasuras, Rastros", de 2016, é, de uma 
Cadernos de Literatura Comparada

O cavo amor e seus ruídos

só vez, uma ética "na medida em que supõe uma escrita dupla, um espaço de abertura e interpenetração, em que o eu-tu fala consigo mesmo ao mesmo tempo em que fala com todos nós, exteriores-interiores à escrita (e ao poema). Ser é escrever e ser escrito. É subcrever-se" (Sterzi 2016: 48).

10 Tentei discutir o aspecto da despersonalização do eu no ensaio "Max Martins: Da poesia como diário de outrem”, de 2018. 11 Combinação de versos do poema "Isto por aquilo", do livro 6o/35, de Max Martins.

\section{Bibliografia}

Aquino, André de (2018), "Max Martins: Da poesia como diário de outrem", Em Tese, v. 24, no 03, Programa de Pós-graduação em Estudos Literários da UFMG, 89-99, <http://www. periodicos.letras.ufmg.br/index.php/emtese/issue/view/701/showToc> (último acesso em 01/07/2020).

Alencar, Melissa da Costa (2011), 1952: A poesia de O Estranho de Max Martins, Belém, Dissertação de Mestrado, Programa de Pós-Graduação em Letras da UFPA.

Alonso Jr., Wenceslau Otero (2019), Estilo poético na obra de Max Martins, São Paulo, Tese de Doutorado, Programa de Pós-Graduação em Filologia e Língua Portuguesa da USP.

Andrade, Carlos Drummond de (2012), A Rosa do Povo, São Paulo, Companhia das Letras.

- - (2002), Carlos Drummond de Andrade: Poesia Completa, Rio de Janeiro, Nova Aguilar.

Arrigucci Jr., Davi (2015), "A outra margem de Marahu", in Martins, Max, Caminho de Marahu, Belém, Editora da UFPA.

-- (2002), Coração partido: uma análise da poesia reflexiva de Drummond, São Paulo, Cosac \& Naify.

- - (2019), "O difícil desafio: a busca poética de Max Martins", in Max Martins em Colóquio, Org. Age de Carvalho/ Mayara Ribeiro Guimarães, Rio de Janeiro, 7Letras.

-- (2014), "O Amor Em seus abismos: A poesia erótica de Max Martins", in Piauí, Questões Poéticas, Edição 99, dez. 2014, <https://piaui.folha.uol.com.br/materia/o-amor-emseus-abismos/>, (último acesso em 01/07/2020).

Camilo, Vagner (2001), Drummond: Da Rosa do Povo à Rosa das Trevas, São Paulo, Ateliê Editorial. Candido, Antonio (1995), "Inquietudes na Poesia de Drummond", in Vários escritos, São Paulo, Duas Cidades.

Gledson, John (2003), Influências e impasses: Drummond e alguns contemporâneos, São Paulo, Companhia das Letras.

Lima, Luiz Costa (2020), "Max Martins: A excepcionalidade paraense", in revista Cult, 24 de junho de 2020. <https://revistacult.uol.com.br/home/max-martins-luiz-costa-lima/?fb clid=IwAR2xXU3twNdQb45RWBG7mLhgrweoBwvaDMunWMMpPiIJIde5iksa2hp9BM>, (último acesso em 24/07/2020).

-- (1995), Lira Antilira: Mário, Drummond, Cabral, Rio de Janeiro, Topbooks. 
Martins, Max (2001), Poemas Reunidos, 1952-2001, Belém, Editora da UFPA.

Merquior, José Guilherme (2012), Verso Universo em Drummond, tradução de Marly de Oliveira, São Paulo, É Realizações.

Nunes, Benedito (2001), "Max Martins, Mestre-Aprendiz", in Martins, Max, Poemas reunidos, Belém, Editora da UFPA.

Sterzi, Eduardo (2016), "Max Martins: Riscos, Rasuras, Rastros", in Scramin, Susana, Alteridades na poesia: Riscos, aberturas, sobrevivências, São Paulo, Iluminuras.

Valéry, Paul (1991), "Poesia e pensamento abstrato", in Variedades, tradução de Maíza Martins Siqueira, São Paulo, Iluminuras.

Vieira, Paulo (2014), Arte, erotismo, natureza e amizade: Os diários de Max Martins, Tese de Doutorado, São Paulo, Programa de Pós-Fraduação em Literatura Brasileira da USP.

Wisnik, José Miguel (2018), Maquinação do Mundo: Drummond e a Mineração, São Paulo, Companhia das Letras. 